\title{
Soybean-Macrophomina phaseolina-Specific Interactions and Identification of a Novel Source of Resistance
}

\author{
Sebastián Reznikov, María A. Chiesa, Esteban M. Pardo, Vicente De Lisi, Noelia Bogado, Victoria González, Fernando \\ Ledesma, Eligio N. Morandi, L. Daniel Ploper, ${ }^{\dagger}$ and Atilio P. Castagnaro ${ }^{\dagger}$
}

First, third, fourth, sixth, seventh, ninth, and tenth authors: Instituto de Tecnología Agroindustrial del Noroeste Argentino (ITANOA), Estación Experimental Agroindustrial Obispo Colombres (EEAOC)-Consejo Nacional de Investigaciones Científicas y Técnicas (CONICET), Av. William Cross 3150, C.P. T4101XAC Las Talitas, Tucumán, Argentina; second and eighth authors: Laboratorio de Fisiología Vegetal, Instituto de Investigaciones en Ciencias Agrarias de Rosario (IICAR), Universidad Nacional de Rosario (UNR) -CONICET, Parque Villarino S/N, 2125 Zavalla, Santa Fe, Argentina; and fifth author: Instituto Paraguayo de Tecnología Agraria (IPTA), Centro de Investigación Capitán Miranda, Ruta VI, Km 16, C.P. 6990 Capitán Miranda, Itapúa, Paraguay.

Accepted for publication 12 July 2018.

\begin{abstract}
Charcoal rot, caused by the fungus Macrophomina phaseolina, is an economically important disease of soybean (Glycine max) worldwide. Objectives of the present research were to (i) study the genetic and pathogenic diversity in a collection of $M$. phaseolina isolates from Argentina and Paraguay and (ii) develop an improved in vitro phenotyping method to evaluate disease response of soybean genotypes to $M$. phaseolina isolates. Cluster analysis showed no clear association among simple sequence repeat profiles, year of collection, pathogenicity, and geographical origin of the isolates from Argentina and Paraguay. Subsequently, the

response of four soybean genotypes against seven $M$. phaseolina isolates was evaluated in the field and the results were confirmed using the in vitro assay developed. This assay, which is based on root disease development on soybean seedlings, allowed the detection of a differential level of aggressiveness among the isolates on four soybean genotypes. The results suggest the existence of specific interactions among soybean genotypes and M. phaseolina isolates. In addition, cultivar Munasqa RR showed a superior response against M. phaseolina compared with DT 97-4290 (moderately resistant), thus becoming a novel source of resistance to charcoal rot.
\end{abstract}

Macrophomina phaseolina (Tassi) Goid. is a polyphagous fungus, infecting nearly 500 species in more than 100 plant families worldwide (Mihail and Taylor 1995), including cereal, legume, vegetable, fruit, and fiber crops (Dhingra and Sinclair 1978). In soybean (Glycine max (L.) Merr.), M. phaseolina is the causal agent of charcoal rot, an economically serious and potentially destructive disease; in 2006, it was estimated to be responsible for yield losses of approximately $4 \%$ worldwide (Wrather et al. 2010). Measurements in experimental field plots recorded losses between 18 and $30 \%$ caused by this fungus (Mengistu et al. 2011). In South America, charcoal rot has caused severe problems in soybean crops in Paraguay, where the prevalence of the disease was $100 \%$ in 48 localities evaluated from April to August 2008 (Orrego Fuente et al. 2009). In Argentina, the hot and dry weather that prevailed in the northwestern region (NW) during the 2000-01, 2011-12, and 2012-13 growing seasons favored charcoal rot development in soybean crops. This affected the production areas in the provinces of Catamarca, Salta, Santiago del Estero, and Tucumán in the NW, resulting in varying levels of yield losses, and even total losses in some fields (Ploper et al. 2001; Reznikov 2016).

†Corresponding authors: L. D. Ploper; E-mail: dt@eeaoc.org.ar, and A. P. Castagnaro; E-mail: atiliocastagnaro@gmail.com and atilio@eeaoc.org.ar

Funding: This study was supported by grants from Estación Experimental Agroindustrial Obispo Colombres (EEAOC) GRF1 project; Ministerio de Ciencia, Tecnología e Innovación Productiva (MinCyT), Plataforma BiotecSur-UE, Proyecto BiotecSojaSur I number 127119; Proyecto Investigación Regional MERCOSUR BiotecSojaSur II-Convenio MinCyT Fundación InnovaT (2012), Acta Comp. number 52; and EEAOC Agencia Nacional de Promoción Científica y Tecnológica (ANPCyT) (2012) PICT 2261 and PICTO 35332. S. Reznikov was awarded a scholarship by CONICET; and M. A. Chiesa, E. N. Morandi, L. D. Ploper, and A. P. Castagnaro are CONICET Career Researchers.

S. Reznikov and M. A. Chiesa contributed equally to this work.

C 2019 The American Phytopathological Society
The use of resistant cultivars provides an effective approach for disease control, particularly for charcoal rot (Romero-Luna et al. 2017). In addition, genetic resistance is a key strategy that minimizes the use of fungicides, reduces crop losses and supports, sustainable production management (Bowen and Schapaugh 1989; Bristow and Wyllie 1984; Smith and Carvil 1997). However, to date, the germplasm line DT $97-4290$ is the only soybean genotype registered as moderately resistant to M. phaseolina (Paris et al. 2006).

Genetic and pathogenic diversity in the species M. phaseolina was previously observed (Su et al. 2001). Recently, genetic diversity among isolates of $M$. phaseolina collected mainly from soybean fields in the United States was determined using simple sequence repeat (SSR) markers (Baird et al. 2009, 2010), and an association between $M$. phaseolina and plant-host origin of the isolates was found (Arias et al. 2011). Similar results were reported with the use of universal rice primers for polymerase chain reaction (PCR) fragment amplification, when analyzing the diversity of isolates from three different crop species (Jana et al. 2005). Saleh et al. (2010) reached the same conclusion through random amplification of genomic fragments by using oligo repeats comparing crops with wild host species.

In order to screen the disease reaction of soybean genotypes to this pathogen accurately, a precise and reproducible phenotyping method is required. To this day, the best method to evaluate host resistance to charcoal rot has been the analysis of root and stem severity at the R7 growth stage based on a CFU index in field conditions (Mengistu et al. 2007). However, this method is not only time consuming and expensive but also requires artificial inoculation of the soil with $M$. phaseolina. These limitations make this method difficult to be used consistently when evaluating the reaction of large numbers of soybean genotypes against charcoal rot.

The underlying hypothesis of the current study was the existence of genotype-genotype specific interactions between soybean germplasm and $M$. phaseolina isolates. In order to validate these 
interactions, the specific aims of this research were to (i) characterize the genetic diversity and aggressiveness of M. phaseolina isolates collected from soybean fields in Paraguay and Argentina, and (ii) develop a rapid and reliable in vitro assay to evaluate and confirm specific responses of soybean genotypes to $M$. phaseolina isolates.

\section{MATERIALS AND METHODS}

Fungal isolates and growth conditions. Thirty-nine isolates of $M$. phaseolina were obtained from roots and stems of soybean plants showing characteristic symptoms of charcoal rot in fields from Argentina and Paraguay in 2008, 2009, 2010, and 2013 (Table 1). The geographic areas were selected based on their importance regarding soybean production in each region (Fig. 1).

All plant samples were rinsed with deionized water, and $0.5-\mathrm{cm}$ tissue sections were surface disinfested with $70 \%$ (vol $/ \mathrm{vol}$ ) ethanol for $30 \mathrm{~s}$ followed by $5 \%$ (vol/vol) $\mathrm{NaClO}$ for $1 \mathrm{~min}$, rinsed with sterile water, then air dried in sterile conditions. Samples were placed on potato dextrose agar (PDA; Difco, Detroit) dishes, acidified with $0.2 \%$ (vol/vol) lactic acid, and incubated at $28 \pm 2{ }^{\circ} \mathrm{C}$ for 4 days. A single microsclerotium of each isolate was removed with a sterile needle under the stereoscopic microscope and transferred to a new acidified PDA dish. Pure cultures of each isolate were obtained in 24 to $48 \mathrm{~h}$ and preserved at $-20^{\circ} \mathrm{C}$ on filter paper.

Nucleic acid purification. Fungal DNA was extracted by employing the cetyltrimethylammonium bromide method for total nucleic acid extraction (Murray and Thompson 1980). First, mycelium was grown in $100 \mathrm{ml}$ of potato-glucose broth for 2 weeks in darkness at $28 \pm 2^{\circ} \mathrm{C}$. Then, it was harvested by filtration through a layer of metal filter $(1 \mathrm{~mm})$, washed twice with sterile water, and dried at room temperature in sterile conditions for $24 \mathrm{~h}$. Dry mycelium was ground with liquid nitrogen using a mortar and pestle, and $100 \mathrm{mg}$ of each sample was used for total nucleic acid extraction.

PCR amplification of SSR markers. Genotypic analysis of 39 M. phaseolina isolates was performed using the 28 SSR primers reported by Arias et al. (2011): StvMPh_209a,StvMPh_213a, StvMPh_329a, StvMPh_415b, StvMPh_114a,StvMPh_146a, StvMPh_100a, StvMPh_102a, StvMPh_144a, StvMPh_162a, StvMPh_173a, StvMPh_190a, StvMPh_19b, StvMPh_20a, StvMPh_34a, StvMPh_132a, StvMPh_49a, StvMPh_63a, StvMPh_182a, StvMPh_197a, StvMPh_310a, StvMPh_461a, StvMPh_484a,StvMPh_562c,StvMPh_109b,StvMPh_116a, StvMPh_123a, and StvMPh_137a. Primers labeled with 6-carboxyfluorescein (FAM) (IDT Technologies, Coralville, IA) were used for amplification of $10 \mathrm{ng}$ of fungal DNA using Titanium Taq DNA Polymerase (Clontech, Fremont, CA) in 5- $\mu$ l reactions in a thermal cycler using the following amplification scheme: $95^{\circ} \mathrm{C}$ for $1 \mathrm{~min}$, $60^{\circ} \mathrm{C}$ for $1 \mathrm{~min}\left(2\right.$ cycles), $95^{\circ} \mathrm{C}$ for $30 \mathrm{~s}, 60^{\circ} \mathrm{C}$ for $30 \mathrm{~s}, 68^{\circ} \mathrm{C}$ for $30 \mathrm{~s}$ (27 cycles), and a final extension cycle at $68^{\circ} \mathrm{C}$ for $4 \mathrm{~min}$. Fluorescently labeled amplified PCR fragments were analyzed on an ABI 3730XL DNA Analyzer (Applied Biosystems, Foster City, CA).

Genetic cluster analysis. For SSR markers, amplicons were screened for length polymorphisms and transformed into binary data for each locus based on the presence $(=1)$ or absence $(=0)$ of alleles. For each SSR marker, the number of amplified alleles, the

TABLE 1. Isolates of Macrophomina phaseolina from Argentina and Paraguay characterized in this study ${ }^{\mathrm{z}}$

\begin{tabular}{|c|c|c|c|c|c|}
\hline Isolate & Locality & Municipality & Coordinates & Country & Year \\
\hline Mp01 & San Agustín & Tucumán & $26^{\circ} 49^{\prime} 24.2^{\prime \prime} \mathrm{S}, 64^{\circ} 51^{\prime} 00.9^{\prime \prime} \mathrm{W}$ & Argentina & 2008 \\
\hline Mp02 & San Agustín & Tucumán & $26^{\circ} 49^{\prime} 30.1^{\prime \prime} \mathrm{S}, 64^{\circ} 51^{\prime} 00.5^{\prime \prime} \mathrm{W}$ & Argentina & 2008 \\
\hline Mp03 & San Agustín & Tucumán & $26^{\circ} 49^{\prime} 33.6^{\prime \prime} \mathrm{S}, 64^{\circ} 51^{\prime} 09.0^{\prime \prime} \mathrm{W}$ & Argentina & 2008 \\
\hline Mp05 & San Agustín & Tucumán & $26^{\circ} 49^{\prime} 36.6^{\prime \prime} \mathrm{S}, 64^{\circ} 51^{\prime} 01.8^{\prime \prime} \mathrm{W}$ & Argentina & 2009 \\
\hline Mp06 & Reconquista & Santa Fe & $29^{\circ} 12^{\prime} 36.9^{\prime \prime} \mathrm{S}, 59^{\circ} 56^{\prime} 23.6^{\prime \prime} \mathrm{W}$ & Argentina & 2009 \\
\hline Mp07 & San Agustín & Tucumán & $26^{\circ} 49^{\prime} 22.8^{\prime \prime} \mathrm{S}, 64^{\circ} 51^{\prime} 36.2^{\prime \prime} \mathrm{W}$ & Argentina & 2009 \\
\hline Mp08 & Tres Arroyos & Buenos Aires & $38^{\circ} 22^{\prime} 38.6^{\prime \prime} \mathrm{S}, 60^{\circ} 20^{\prime} 24.5^{\prime \prime} \mathrm{W}$ & Argentina & 2009 \\
\hline Mp10 & Arenales & Santiago del Estero & $26^{\circ} 41^{\prime} 37.1^{\prime \prime} \mathrm{S}, 64^{\circ} 30^{\prime} 47.9^{\prime \prime} \mathrm{W}$ & Argentina & 2009 \\
\hline Mp12 & Juan N. Fernández & Buenos Aires & $37^{\circ} 59^{\prime} 34.6^{\prime \prime} \mathrm{S}, 59^{\circ} 15^{\prime} 39.7^{\prime \prime} \mathrm{W}$ & Argentina & 2009 \\
\hline Mp13 & Santa Teresita & Tucumán & $26^{\circ} 40^{\prime} 20.0^{\prime \prime} \mathrm{S}, 64^{\circ} 30^{\prime} 46.7^{\prime \prime} \mathrm{W}$ & Argentina & 2010 \\
\hline Mp14 & Piedra Buena & Tucumán & $26^{\circ} 44^{\prime} 15.1^{\prime \prime} \mathrm{S}, 64^{\circ} 39^{\prime} 26.6^{\prime \prime} \mathrm{W}$ & Argentina & 2010 \\
\hline Mp15 & San Agustín & Tucumán & $26^{\circ} 49^{\prime} 15.1^{\prime \prime} \mathrm{S}, 64^{\circ} 51^{\prime} 33.8^{\prime \prime} \mathrm{W}$ & Argentina & 2010 \\
\hline Mp16 & San Agustín & Tucumán & $26^{\circ} 49^{\prime} 41.9^{\prime \prime} \mathrm{S}, 64^{\circ} 51^{\prime} 31.4^{\prime \prime} \mathrm{W}$ & Argentina & 2010 \\
\hline Mp17 & Piedra Buena & Tucumán & $26^{\circ} 44^{\prime} 05.6^{\prime \prime} \mathrm{S}, 64^{\circ} 40^{\prime} 19.4^{\prime \prime} \mathrm{W}$ & Argentina & 2010 \\
\hline Mp18 & San Agustín & Tucumán & $26^{\circ} 49^{\prime} 24.5^{\prime \prime} \mathrm{S}, 64^{\circ} 51^{\prime} 06.3^{\prime \prime} \mathrm{W}$ & Argentina & 2010 \\
\hline Mp19 & Arenales & Santiago del Estero & $26^{\circ} 41^{\prime} 35.3^{\prime \prime} \mathrm{S}, 64^{\circ} 31^{\prime} 41.5^{\prime \prime} \mathrm{W}$ & Argentina & 2010 \\
\hline Mp20 & Arenales & Santiago del Estero & $26^{\circ} 41^{\prime} 20.2^{\prime \prime} \mathrm{S}, 64^{\circ} 33^{\prime} 02.8^{\prime \prime} \mathrm{W}$ & Argentina & 2010 \\
\hline Mp23 & Arenales & Santiago del Estero & $26^{\circ} 40^{\prime} 52.1^{\prime \prime} \mathrm{S}, 64^{\circ} 32^{\prime} 06.6^{\prime \prime} \mathrm{W}$ & Argentina & 2010 \\
\hline $\mathrm{Mp} 24$ & El Palomar & Santiago del Estero & $26^{\circ} 51^{\prime} 06.9^{\prime \prime} \mathrm{S}, 64^{\circ} 42^{\prime} 23.7^{\prime \prime} \mathrm{W}$ & Argentina & 2010 \\
\hline Mp25 & Piedra Blanca & Tucumán & $26^{\circ} 43^{\prime} 39.2^{\prime \prime} \mathrm{S}, 64^{\circ} 47^{\prime} 44.1^{\prime \prime} \mathrm{W}$ & Argentina & 2010 \\
\hline Mp26 & Piedra Blanca & Tucumán & $26^{\circ} 44^{\prime} 02.5^{\prime \prime} \mathrm{S}, 64^{\circ} 47^{\prime} 12.0^{\prime \prime} \mathrm{W}$ & Argentina & 2010 \\
\hline Mp27 & San Agustín & Tucumán & $26^{\circ} 49^{\prime} 54.3^{\prime \prime} \mathrm{S}, 64^{\circ} 51^{\prime} 29.8^{\prime \prime} \mathrm{W}$ & Argentina & 2010 \\
\hline Mp32 & Chore & Chore & $24^{\circ} 10^{\prime} 24.7^{\prime \prime} \mathrm{S}, 56^{\circ} 34^{\prime} 47.1^{\prime \prime} \mathrm{W}$ & Paraguay & 2013 \\
\hline Mp33 & Chore & Chore & $24^{\circ} 11^{\prime} 39.9^{\prime \prime} \mathrm{S}, 56^{\circ} 34^{\prime} 54.1^{\prime \prime} \mathrm{W}$ & Paraguay & 2013 \\
\hline Mp34 & Chore & Chore & $24^{\circ} 11^{\prime} 17.3^{\prime \prime} \mathrm{S}, 56^{\circ} 37^{\prime} 05.4^{\prime \prime} \mathrm{W}$ & Paraguay & 2013 \\
\hline Mp35 & Chore & Chore & $24^{\circ} 11^{\prime} 38.6^{\prime \prime} \mathrm{S}, 56^{\circ} 37^{\prime} 45.9^{\prime \prime} \mathrm{W}$ & Paraguay & 2013 \\
\hline Mp36 & Chore & Chore & $24^{\circ} 11^{\prime} 41.3^{\prime \prime} \mathrm{S}, 56^{\circ} 34^{\prime} 16.6^{\prime \prime} \mathrm{W}$ & Paraguay & 2013 \\
\hline Mp37 & Capitán Miranda & Capitán Miranda & $27^{\circ} 13^{\prime} 04.1^{\prime \prime} \mathrm{S}, 55^{\circ} 46^{\prime} 49.2^{\prime \prime} \mathrm{W}$ & Paraguay & 2013 \\
\hline Mp39 & Capitán Miranda & Capitán Miranda & $27^{\circ} 13^{\prime} 01.4^{\prime \prime} \mathrm{S}, 55^{\circ} 46^{\prime} 21.6^{\prime \prime} \mathrm{W}$ & Paraguay & 2013 \\
\hline Mp40 & Yhovy & Yhovy & $24^{\circ} 17^{\prime} 52.0^{\prime \prime} \mathrm{S}, 54^{\circ} 58^{\prime} 47.9^{\prime \prime} \mathrm{W}$ & Paraguay & 2013 \\
\hline Mp41 & Yhovy & Yhovy & $24^{\circ} 17^{\prime} 47.7^{\prime \prime} \mathrm{S}, 54^{\circ} 58^{\prime} 57.7^{\prime \prime} \mathrm{W}$ & Paraguay & 2013 \\
\hline Мp42 & Yhovy & Yhovy & $24^{\circ} 18^{\prime} 02.7^{\prime \prime} \mathrm{S}, 5^{\circ} 00^{\prime} 15.1^{\prime \prime} \mathrm{W}$ & Paraguay & 2013 \\
\hline Mp43 & Yhovy & Yhovy & $24^{\circ} 17^{\prime} 52.4^{\prime \prime} \mathrm{S}, 55^{\circ} 00^{\prime} 10.1^{\prime \prime} \mathrm{W}$ & Paraguay & 2013 \\
\hline Mp44 & Yhovy & Yhovy & $24^{\circ} 18^{\prime} 22.9^{\prime \prime} \mathrm{S}, 55^{\circ} 00^{\prime} 05.5^{\prime \prime} \mathrm{W}$ & Paraguay & 2013 \\
\hline Mp45 & San Juan Bautista & San Juan Bautista & $26^{\circ} 40^{\prime} 14.7^{\prime \prime} \mathrm{S}, 57^{\circ} 07^{\prime} 24.8^{\prime \prime} \mathrm{W}$ & Paraguay & 2013 \\
\hline Mp46 & San Juan Bautista & San Juan Bautista & $26^{\circ} 39^{\prime} 43.3^{\prime \prime} \mathrm{S}, 57^{\circ} 07^{\prime} 18.9^{\prime \prime} \mathrm{W}$ & Paraguay & 2013 \\
\hline Mp47 & San Juan Bautista & San Juan Bautista & $26^{\circ} 40^{\prime} 22.6^{\prime \prime} \mathrm{S}, 57^{\circ} 09^{\prime} 58.2^{\prime \prime} \mathrm{W}$ & Paraguay & 2013 \\
\hline Mp48 & San Juan Bautista & San Juan Bautista & $26^{\circ} 40^{\prime} 52.0^{\prime \prime} \mathrm{S}, 57^{\circ} 05^{\prime} 45.7^{\prime \prime} \mathrm{W}$ & Paraguay & 2013 \\
\hline Мp49 & San Juan Bautista & San Juan Bautista & $26^{\circ} 40^{\prime} 47.2^{\prime \prime} \mathrm{S}, 57^{\circ} 06^{\prime} 02.6^{\prime \prime} \mathrm{W}$ & Paraguay & 2013 \\
\hline
\end{tabular}

${ }^{\mathrm{z}}$ Provinces of Argentina and districts of Paraguay, respectively. Data in bold indicate the M. phaseolina isolates tested in the pathogenicity assays. 
size range (in base pairs), the number of polymorphic alleles, and the polymorphism information content (PIC) were calculated (Milbourne et al. 1997). In addition, Info-Gen software (Balzarini and Di Rienzo 2013) was used to estimate the percentage of polymorphism (band or locus), the average number of alleles per primer set or per locus, the effective number of alleles, and Nei's genetic diversity (Nei 1973). Cluster analysis of M. phaseolina isolates was performed using the unweighted pair-group method with arithmetic averages with the SSR data in Info-Gen. To evaluate the robustness of the diversity analysis and the clusters formed, the binary data set was subjected to 1,000 bootstrapping replicates using the WINBOOT program (Yap and Nelson 1996), and confidence values higher than 50\% were indicated (Highton 1993).

Pathogenicity of $M$. phaseolina isolates in field conditions. A field test to evaluate the pathogenicity of $M$. phaseolina isolates was conducted at the Capitán Miranda Research Center within Instituto Paraguayo de Tecnología Agraria, Capitán Miranda, Itapúa, Paraguay $\left(27^{\circ} 11^{\prime} 59.92^{\prime \prime} \mathrm{S}\right.$ and $\left.55^{\circ} 47^{\prime} 28.90^{\prime \prime} \mathrm{W}\right)$. The trial was planted by hand on 16 January 2013 with four soybean genotypes from different maturity groups (MG): DT 97-4290 and CRIA 4 (MG IV), DM 6.2i
RR (MG VI), and Munasqa RR (MG VIII). Soybean genotype DT 974290 was the moderately resistant control (Paris et al. 2006) and DM $6.2 \mathrm{i} R \mathrm{R}$ was the susceptible control. The experimental design was a blocked split plot with three replicates, in which $M$. phaseolina isolates were assigned to the whole plots and soybean genotypes to the subplots, each of which consisted of four 1-m rows, spaced $0.5 \mathrm{~m}$ apart, and planted at a density of 23 seeds $/ \mathrm{m}$. As inoculum, seven isolates of M. phaseolina (Mp15, Mp17, and Mp18 from Argentina and Mp32, Mp37, Mp42, and Mp48 from Paraguay) (Table 1) were used to inoculate sterile millet, which was then incubated for 20 days at $30^{\circ} \mathrm{C}$ in darkness to stimulate the development of microsclerotia. When soybean seed were planted, $5 \mathrm{~g}$ of millet colonized with each isolate of M. phaseolina was applied by hand per linear meter. At the R7 growth stage (Fehr et al. 1971), disease severity was estimated on 10 plants per plot using the scale established by Paris et al. (2006): $1=$ no discoloration and no microsclerotia visible; $2=$ no discoloration of vascular tissue, with very few microsclerotia visible in the pith, vascular tissue or under the epidermis; $3=$ partially discolored vascular tissue, with microsclerotia partially covering the tissue; $4=$ discolored vascular tissue, with numerous microsclerotia visible in

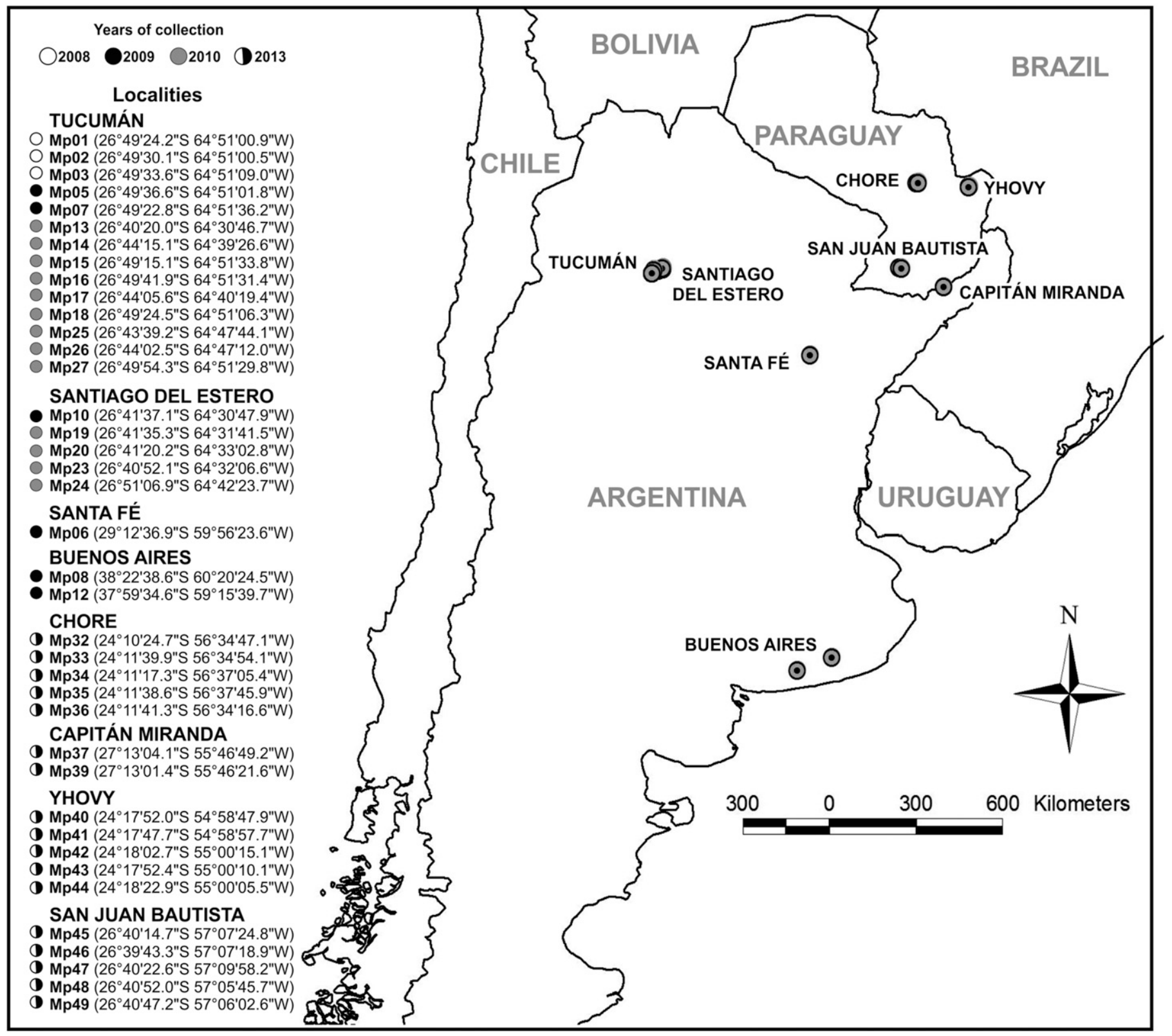

Fig. 1. Location of the sampling regions of the 39 Macrophomina phaseolina isolates during the 2008, 2009, 2010, and 2013 cropping seasons in Argentina and Paraguay. 
the tissue under the outer epidermis, in stem and root sections; and $5=$ vascular tissue with numerous microsclerotia producing a dark color inside and outside of the stem and root tissue. In addition, CFU of the pathogen per gram of root tissue (CFU/g) was determined on the same 10 plants, according to Mengistu et al. (2007). Briefly, plant samples were obtained by cutting $10 \mathrm{~cm}$ above and below the soil line including root and stem tissue. Three rinses with tap water were performed to remove traces of soil from the samples, which were then dried at room temperature and ground. From each sample, 5 $\mathrm{mg}$ of ground tissue was placed in a test tube and disinfested with 5\% (vol/vol) $\mathrm{NaClO}$ for $1 \mathrm{~min}$, followed by three 1-min washes using sterile distilled water. Subsequently, $5 \mathrm{ml}$ of $60^{\circ} \mathrm{C}$ sterile PDA was added and samples were poured into sterile Petri dishes. Total CFU was quantified after incubation at $28^{\circ} \mathrm{C}$ for 3-5 days, and expressed as CFU per gram of dry tissue, CFU/g. Disease severity at R7 (logtransformed) and CFU/g (square root-transformed) were analyzed by generalized linear mixed models followed by mean comparison (least significant difference [LSD], $P=0.05$ ) with InfoStat software (Di Rienzo et al. 2011).

In vitro method of soybean root infection with $M$. phaseolina. Soybean seed were disinfested with $5 \%$ (vol/vol) $\mathrm{NaClO}$ for $1 \mathrm{~min}$, followed by $70 \%$ (vol/vol) ethanol for $30 \mathrm{~s}$ and three 1-min rinses with sterile distilled water. Disinfected seed were placed in a Petri dish containing a layer of sterile filter paper, to which $15 \mathrm{ml}$ of sterile distilled water was added. Seed were incubated for $48 \mathrm{~h}$ at $28^{\circ} \mathrm{C}$ in darkness in order to induce germination. Next, five healthy germinated seed were placed in a sterilized glass flasks $(15 \mathrm{~cm}$ high and $10 \mathrm{~cm}$ diameter) containing a $3 \mathrm{~cm}$ layer of cotton and filter paper and $50 \mathrm{ml}$ of sterile distilled water. Three toothpick pieces ( $2 \mathrm{~cm}$ long) colonized with a $M$. phaseolina isolate derived from a single microsclerotium were added to each flask in a sterile flow chamber. The flasks containing the germinated and inoculated soybean seed were kept in a growth chamber under a 16-h light $\left(600 \mu \mathrm{E} \mathrm{m}^{-2} \mathrm{~s}^{-1}\right) / 8$-h dark regime and a temperature of $30^{\circ} \mathrm{C}$.

The in vitro infection method was conducted at the Plant Physiology Laboratory of the Instituto de Investigaciones en Ciencias Agrarias de Rosario (IICAR), Universidad Nacional de Rosario
(UNR) and Consejo Nacional de Investigaciones Científicas y Tecnológicas (CONICET), located in Zavalla, Santa Fe, Argentina. The root infection severity of four soybean cultivars: DT 97-4290 and CRIA 4 (MG IV), DM 6.2i RR (MG VI) and Munasqa RR (MG VIII) was tested with seven single-microsclerotium isolates of M. phaseolina (Mp15, Mp17, Mp18, Mp32, Mp37, Mp42 and Mp48) (Table 1). Root disease severity was evaluated every $48 \mathrm{~h}$ for 12 days; to do this, images were acquired with a digital camera (Nikon D50) and the length of necrosis in the root system was measured for each seedling with an image-processing program (ImageJ; NIH, Bethesda, MD). Disease severity values were expressed as a percentage of necrosis of the root system.

The experimental design was a randomized complete block with three replicates, and was repeated twice. Each replication consisted of three flasks, each containing five germinated seeds. Two flasks contained the germinated seed inoculated with M. phaseolina (10 experimental units) and the control sample flask contained the noninoculated germinated seed (5 experimental units). The area under the disease progress curve (AUDPC) was calculated based on disease severity data (Madden et al. 2007) and analyzed by generalized linear mixed models followed by mean comparison (LSD, $P=0.05$ ) with InfoStat software (Di Rienzo et al. 2011). To determine the predictive ability of the in vitro assay, Spearman's rank correlation coefficients were calculated between in vitro AUDPC value and field disease severity or field CFU/g values using InfoStat software (Di Rienzo et al. 2011).

\section{RESULTS}

Genetic relationships among $M$. phaseolina isolates. For each SSR marker, information on the number of amplified alleles (1 to 14 ), the size range (91 to $270 \mathrm{bp}$ ), the number of polymorphic alleles ( 0 to 14$)$, and PIC (-0.710 to 0.841$)$ are presented in Table 2. When the $39 \mathrm{M}$. phaseolina isolates were genotypically analyzed with 28 SSR markers, 213 amplicons were obtained, of which 155 $(72.8 \%)$ were polymorphic. The value of Nei's genetic diversity obtained was 0.13 .

TABLE 2. Summary of genotyping results of 39 isolates of Macrophomina phaseolina from Argentina and Paraguay using 28 simple sequences repeat (SSR) markers

\begin{tabular}{|c|c|c|c|c|}
\hline Locus & Number of alleles & Size range (bp) & Number of polymorphic alleles & $\mathrm{PIC}^{\mathrm{z}}$ \\
\hline StvMPh_209a & 5 & $162-176$ & 5 & 0.7 \\
\hline StvMPh_213a & 6 & $137-166$ & 6 & 0.5 \\
\hline StvMPh_329a & 9 & $96-181$ & 9 & 0.7 \\
\hline StvMPh_114a & 7 & $168-203$ & 7 & 0.7 \\
\hline StvMPh_146a & 4 & $91-120$ & 4 & 0.5 \\
\hline StvMPh_100a & 2 & $174-176$ & 2 & -0.7 \\
\hline StvMPh_102a & 3 & $179-183$ & 3 & 0.6 \\
\hline StvMPh_173a & 6 & $122-157$ & 6 & 0.8 \\
\hline StvMPh_190a & 5 & $136-169$ & 5 & 0.5 \\
\hline StvMPh_19b & 5 & $172-185$ & 5 & 0.5 \\
\hline StvMPh_20a & 3 & $165-173$ & 3 & 0.4 \\
\hline StvMPh_34a & 4 & $169-185$ & 4 & 0.4 \\
\hline StvMPh_132a & 10 & $120-166$ & 10 & 0.7 \\
\hline StvMPh_49a & 7 & $117-190$ & 7 & 0.8 \\
\hline StvMPh_461a & 6 & $99-173$ & 6 & 0.7 \\
\hline StvMPh_484a & 13 & $124-270$ & 13 & 0.8 \\
\hline StvMPh_562c & 5 & $116-184$ & 5 & 0.7 \\
\hline StvMPh_109b & 3 & $133-169$ & 3 & 0.1 \\
\hline StvMPh_116a & 7 & $103-138$ & 7 & 0.5 \\
\hline StvMPh_123a & 3 & $159-164$ & 3 & 0.4 \\
\hline StvMPh_137a & 3 & $172-176$ & 3 & 0.5 \\
\hline
\end{tabular}

${ }^{\mathrm{z}}$ Polymorphism information content for each SSR. 
A single-linkage dendrogram was obtained from the SSR marker data. Genetic relationships among isolates were determined by the Jaccard's similarity coefficient (Fig. 2). The cluster analysis showed that isolate Mp18 from Argentina was clearly differentiated from the rest of the isolates at a genetic distance of 0.90 . The rest of the isolates were separated into two major clusters with a 0.80 dissimilarity value. Cluster I harbored the majority of M. phaseolina isolates, including all isolates from Paraguay and 11 from Argentina, whereas cluster II included $10 \mathrm{M}$. phaseolina isolates from Argentina (Fig. 2), 7 from the NW, and the remaining 3 (Mp06, $\mathrm{Mp08}$, and Mp12) from the central region of the country (Table 1; Fig. 1).

Pathogenicity of $M$. phaseolina isolates in field conditions. Seven isolates of $M$. phaseolina from the collection (Table 1) were selected for the pathogenicity tests. These isolates originated from both countries (Mp15, Mp17, and Mp18 from Argentina and Mp32, Mp37, Mp42, and Mp48 from Paraguay) and belonged to the two main clusters in the dendrogram, except for isolate Mp18 from Argentina, which, as stated above, was differentiated from the rest of the isolates (Fig. 2). In addition, the selected isolates showed differences in cultural and growth characteristics (data not shown).

When the seven isolates of M. phaseolina were inoculated on the four soybean genotypes in field conditions, no significant differences in aggressiveness were observed among isolates considering the results of disease severity and CFU/g, for each one as an average in the four soybean genotypes (Table 3 ). Disease severity values ranged from 1.9 to $2.2(P=0.6203)$ and $C F U / g$ values ranged from
233.3 to $611.6(P=0.5015)$. However, when the effect of the soybean genotypes were tested and the disease reaction of each of the four genotypes (DM 6.2i RR, CRIA 4, DT 97-4290, and Munasqa RR) was considered as an average against the seven $M$. phaseolina isolates, significant differences were found in disease severity $(P=0.0001)$ and also in CFU/g values $(P=0.0001)$ (Table 3).

Additionally, the analysis of the soybean genotype-M. phaseolina isolate interactions showed significant effects for both disease severity $(P=0.0277)$ and $\mathrm{CFU} / \mathrm{g}(P=0.0025)$ (Table 3$)$. Contrasting responses were detected in field conditions when the specific interactions between each soybean cultivar inoculated with the different isolates of the pathogen were analyzed in detail (Fig. 3A). The lowest value of CFU/g was obtained in the Munasqa RR $\times$ Mp15 combination (33.3), whereas the highest value of CFU/g was obtained in the DM6.2i RR $\times$ Mp48 combination $(2,366.7)$ (Fig. 3A)

Because the significance of the soybean cultivar-M. phaseolina isolate interaction for disease severity in field conditions was relatively marginal $(P=0.0277)$, the main effects of the cultivars were analyzed (Table 4). Munasqa RR displayed the highest level of resistance among the four genotypes evaluated, although it was not significantly different in disease severity values from DT 97-4290, which was classified as moderately resistant. Both genotypes showed the lowest values of disease severity and differed from CRIA 4 and DM 6.2i RR $(P=0.0001)$. However, DM 6.2i RR was the most susceptible to $M$. phaseolina and was significantly



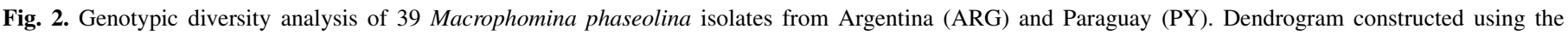

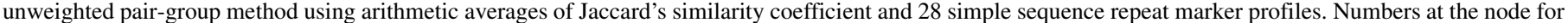

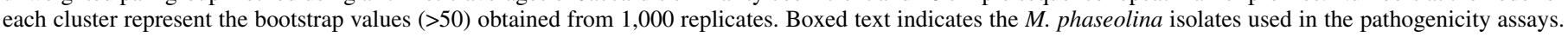


different from CRIA 4, which was classified as moderately susceptible (Table 4).

Pathogenicity of $M$. phaseolina isolates in vitro. Initially, the in vitro root infection assay was optimized with isolate Mp17, and reproducible results were obtained after a 2-week incubation period. At 2 days postinoculation (dpi), no symptoms of necrosis on the radicle of either resistant or susceptible genotypes were observed (Fig. 4). At $5 \mathrm{dpi}$, initial symptoms of necrosis were observed in $60 \%$ of the germinated seed of the susceptible genotype DM 6.2i RR whereas, in $40 \%$ of the initially germinated seed, the germination process was arrested compared with the uninfected germinated seed control. At $9 \mathrm{dpi}$, all seedlings of the two susceptible genotypes (DM 6.2i RR and CRIA 4) showed symptoms of necrosis on the root system, whereas the moderately resistant genotype DT 97-4290 presented initial symptoms of necrosis in $60 \%$ of the seedlings. It is interesting to note that none of the Munasqa RR seedlings showed signs of necrosis in the root system, demonstrating that, in controlled conditions, this genotype also displayed the highest level of resistance. At 12 dpi, clear and reproducible differences were observed between the susceptible genotypes and the moderately resistant genotype DT 97-4290 when compared with Munasqa RR inoculated with isolate Mp17 (Fig. 4). Disease severity, measured as a percentage of necrosis on the root system, was evaluated every $48 \mathrm{~h}$ during $12 \mathrm{dpi}$, allowing the disease progress to be determined in each interaction.

By applying the in vitro phenotyping method previously described, the root disease severity of the same four soybean genotypes (Munasqa RR, DT 97-4290, CRIA 4, and DM 6.2i RR) previously inoculated in field conditions with seven isolates of M. phaseolina (Mp15, Mp17, Mp18, Mp32, Mp37, Mp42, and Mp48) was monitored in controlled conditions. The results obtained in the pathogenicity test are summarized in Table 3 and Figures 3B and 5. Statistical differences were found in the specific interactions among the four soybean genotypes and the seven M. phaseolina isolates, evaluated in controlled conditions $(P=0.0004)$, in accordance with the field trial (Table 3). Contrasting responses

TABLE 3. Results of mixed-model analyses of variance to determine the main effects and interactions of soybean cultivar and Macrophomina phaseolina isolate on CFU/g of tissue and disease severity data obtained in the field and on area under the disease progress curve (AUDPC) obtained in the in vitro assay ${ }^{\mathrm{x}}$

\begin{tabular}{|c|c|c|c|c|c|c|c|c|c|}
\hline \multirow[b]{2}{*}{ Source } & \multicolumn{3}{|c|}{ Field test $(\mathrm{CFU} / \mathrm{g})^{\mathrm{y}}$} & \multicolumn{3}{|c|}{ Field test (disease severity) ${ }^{\mathrm{z}}$} & \multicolumn{3}{|c|}{ In vitro assay (AUDPC) } \\
\hline & df & $F$ & $P$ & df & $F$ & $P$ & df & $F$ & $P$ \\
\hline \multicolumn{10}{|l|}{ Main effects } \\
\hline \multicolumn{10}{|l|}{ Interactions } \\
\hline Cultivar $\times$ isolate & 18 & 2.40 & 0.0025 & 18 & 1.77 & 0.0277 & 18 & 3.23 & 0.0004 \\
\hline
\end{tabular}

${ }^{x}$ Data of CFU/g were transformed to $\sqrt{\mathrm{x}}$ and data of disease severity to $\ln (\mathrm{x})$ before the statistical analysis (least significant difference, $P=0.05$ ).

y Field conditions in Capitán Miranda, Itapúa, Paraguay, during the 2013 growing season.

${ }^{\mathrm{z}}$ Disease severity at R7 stage.

A



B

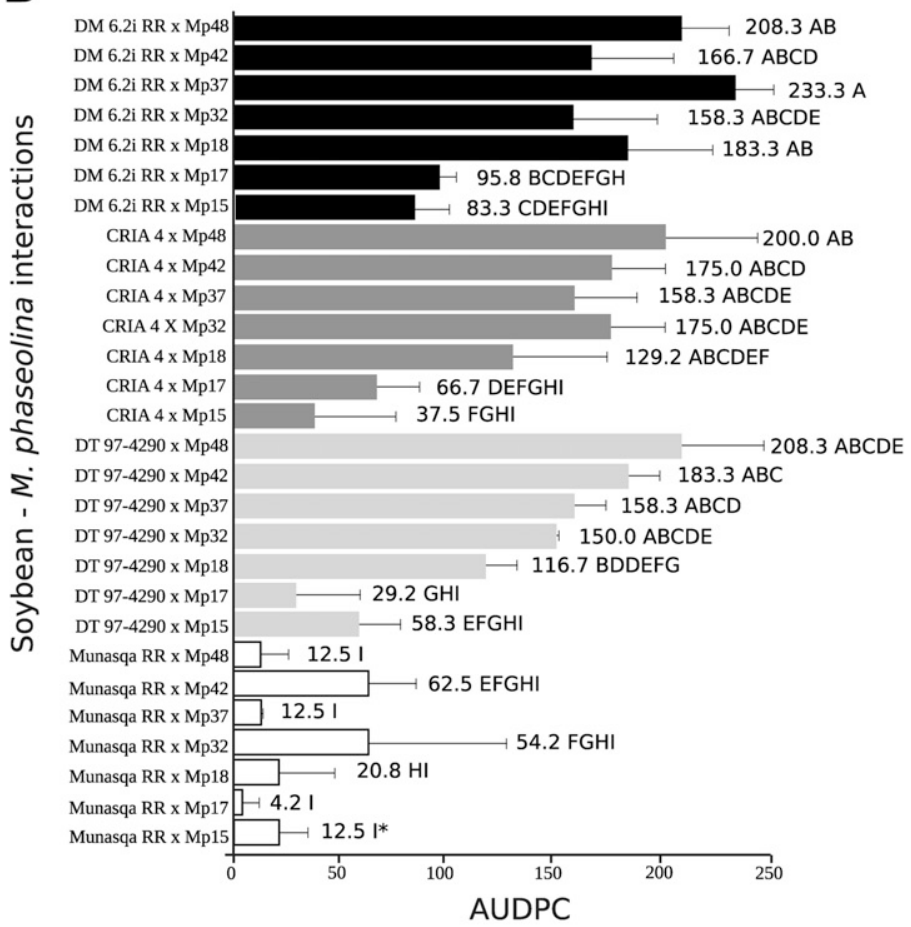

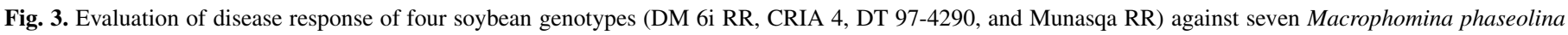

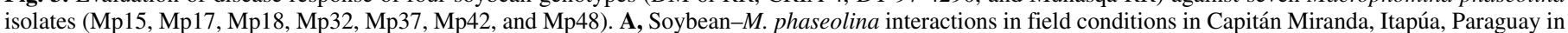

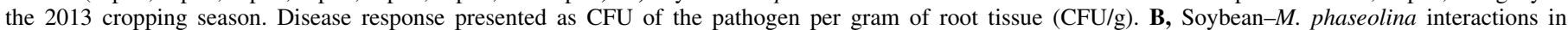



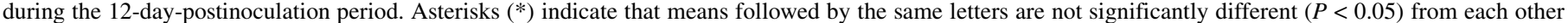
based on two-way mixed-model analysis of variance followed by means separation (least significant difference). 
among the soybean cultivar were also detected in controlled conditions when inoculated with the different isolates of the pathogen (Fig. 3B). Again, Munasqa RR showed the highest level of resistance among the four genotypes evaluated, displaying the lowest values of AUDPC against all the inoculated isolates (Fig. 3B). In controlled conditions, the lowest value of AUDPC was obtained in the Munasqa RR $\times$ Mp17 combination (4.2), whereas the highest value was obtained in the DM6.2i RR $\times$ Mp37 combination (233.3) (Fig. 3B). The contrasting phenotypes observed in some representative specific interactions by applying the in vitro root infection method are shown in Figure 5. Indeed, the in vitro assay data (AUDPC) correlated with the square root-transformed CFU/g field data with a Spearman's rank correlation coefficient value of 0.62 $(P=0.0004)$ (Fig. 6A). In addition, the AUDPC data obtained in controlled conditions correlated with the ln-transformed severity field data with a rank correlation coefficient of $0.59(P=0.0009)$ (Fig. $6 \mathrm{~B})$, validating the in vitro phenotyping method developed and presented in this work.

\section{DISCUSSION}

In this study, the genetic diversity in a collection of 39 isolates of M. phaseolina, an important fungal pathogen that seriously affects soybean crops worldwide, was analyzed. Previous genetic studies using molecular markers and subsequent cluster analysis showed a high degree of global genetic diversity among isolates of this pathogen (Arias et al. 2011; Muñoz-Cabañas et al. 2005). Our cluster analysis, based on 28 SSR markers, revealed two distinct genetic groups and one ungrouped isolate, Mp18, at a genetic distance threshold of 0.80 in the dendrogram. Nevertheless, all of the isolates from different geographical origins and years of collection had a unique and monomorphic allele for SSR marker StvMPh_162a, which has a significant sequence homology to an endoglucanase or a cellulase gene (E-value: $2 \times 10^{-40}$ ) (Arias et al. 2011). Further studies are needed to confirm whether isolate Mp18 might belong to another species, such as the novel species M. pseudophaseolina, reported in Senegal (Sarr et al. 2014).

Our results suggest a certain degree of genetic association between geographical region and isolates, which could be explained by the movement of infected seed throughout the different soybeanproducing regions included in this study. In this sense, all of the M. phaseolina isolates from Paraguay grouped together in cluster I but the isolates from Argentina were separated in both clusters. No clear associations were observed between the year of collection and the SSR profiles. Previously, genetic association among isolates from the same geographical region, where two groups with different genetic profiles and pathogenicity had been isolated from two different geographical regions, was reported from México (Mayék-Pérez et al. 2001). In contrast, other studies have found only a very low association between the genetic profile and geographical origin of M. phaseolina isolates (Baird et al. 2009, 2010; Muñoz-Cabañas et al. 2005).

In the pathogenicity assays in field conditions, disease variables were first analyzed for each inoculated isolate, averaging the data obtained when interacting with the four tested soybean genotypes. No significant differences in aggressiveness were observed between the isolates from Paraguay and Argentina. However, when the results obtained in the same field assay were analyzed for each soybean genotype tested, averaging the data obtained when interacting with the seven inoculated $M$. phaseolina isolates, significant differences were observed. The results obtained in the present study demonstrated that the local elite genotype Munasqa RR exhibited lower values of the disease parameters than the moderately resistant DT 974290 in field conditions. Furthermore, specific interactions among the four soybean genotypes and the seven M. phaseolina isolates evaluated in field conditions were found.

The use of resistant soybean germplasm is the most effective strategy for charcoal rot management (Mengistu et al. 2013b;
Romero-Luna et al. 2017). However, although new sources of genetic resistance need to be identified, very few genotypes were accurately characterized as resistant to $M$. phaseolina in both field and controlled conditions. Previously, the plant introduction (PI) genotypes PI594302, PI567562A, PI506764, and PI567334 were reported as markedly more resistant to $M$. phaseolina infection in field conditions than DT 97-4290, the first genotype described by Paris et al. (2006) as moderately resistant (Mengistu et al. 2013a). Later, three other genotypes (PI548302, PI548414, and PI548178) were also characterized as more resistant against $M$. phaseolina than DT97-4290, using a cut-stem inoculation technique in semicontrolled greenhouse conditions (Pawlowski et al. 2015). However, it is important to note that none of these genotypes is a commercial cultivar with good agronomic traits.

Consequently, in order to corroborate the best performance of the local elite cultivar Munasqa RR and to evaluate the specific interactions observed in the field trial, an improved method for phenotyping the disease response in controlled conditions was developed. The new in vitro method proved to be an effective and reliable technique to assess the disease reaction of multiple soybean genotypes against several M. phaseolina isolates. It is also simple to perform; inexpensive, because does not require culture medium; reproducible; and quick, because the whole process takes no longer than 2 weeks (inoculation of 2-day germinated soybean seed and evaluation after 12 days). In this context, Bressano et al. (2010) used an in vitro method to evaluate the $M$. phaseolina infection process in soybean seedlings (in growth stage V1) by using culture medium and Petri dishes. However, this approach has not been used to evaluate the response of different soybean genotypes to charcoal rot. In addition, the in vitro method developed in this work allows quantifying the progress of the disease without damaging the infected tissue (nondestructive). Furthermore, it is considerably faster than the cut-stem inoculation technique described previously (Twizeyimana et al. 2012), in which each cycle of evaluation takes approximately 8 weeks, not to mention the field evaluation, which requires a full crop season to complete the process (Mengistu et al. 2013b). Moreover, this approach can be used to screen a large number of soybean genotypes, searching for alternative sources of genetic resistance to charcoal rot. Most importantly, environmental variation, which can contribute to inconsistent results between field tests (Mengistu et al. 2013b), can be controlled by using this in vitro approach in growth chambers, further reducing experimental error and improving reliability in the evaluation of resistance to M. phaseolina. The results obtained by this method in controlled conditions were correlated with those obtained in field conditions. Finally, this in vitro infection method evaluates necrosis on the root system, the natural tissue infected by $M$. phaseolina, a soilborne pathogen. Other methods previously described infect leaf

TABLE 4. Assessment of averaged disease response of four soybean genotypes inoculated with seven Macrophomina phaseolina isolates independently and in field conditions in Capitán Miranda, Itapúa, Paraguay during the 2013 cropping season ${ }^{x}$

\begin{tabular}{lcc}
\hline Genotype & Resistance reaction $^{\mathrm{y}}$ & Severity at R7z $^{\mathrm{z}}$ \\
\hline DM 6.2i RR & $\mathrm{S}$ & $3.1 \mathrm{~A}$ \\
CRIA 4 & MS & $2.5 \mathrm{~B}$ \\
DT 97-4290 & MR & $1.6 \mathrm{C}$ \\
Munasqa RR & MR & $1.4 \mathrm{C}$ \\
$P$ & $\ldots$ & $<0.0001$ \\
\hline
\end{tabular}

${ }^{x}$ Data of disease severity were transformed to $\ln (\mathrm{x})$ before the statistical analysis.

y Resistance according to Paris et al. (2006). S = susceptible, MS = moderately susceptible, and MR = moderately resistant.

z Severity of the disease at R7 stage is the average for each genotype inoculated with each of the seven evaluated isolates of M. phaseolina (Mp15, Mp17, Mp18, Mp32, Mp37, Mp42, and Mp48). Statistically significant differences (least significant difference, $P \leq 0.05$ ) in the column are indicated by different capital letters. 
(Mayék-Pérez et al. 2001) or stem (Twizeyimana et al. 2012) tissues. Consequently, the method presented here should be useful to perform more advanced studies such as transcriptomic and metabolomics analysis of this specific plant-pathogen interaction.

In addition to characterizing a novel soybean genotype resistant to charcoal rot (Munasqa RR) and specific interactions between soybean genotypes and different $M$. phaseolina isolates in field conditions, these specific interactions were also observed and analyzed in controlled conditions. Except for Munasqa RR, which showed significantly lower levels of disease response with most of the isolates, the other three analyzed genotypes developed contrasting responses to the different isolates (Fig. 3B). Moreover, crossed specific interactions were observed among DT97-4290 and CRIA4 genotypes with isolates Mp15 and Mp17 (Fig. 3B). On the other hand, isolate Mp37, which showed the same disease response when interacting with DT97-4290 and CRIA4, was also the most aggressive on DM 6.2i RR whereas it was one of the least aggressive on Munasqa RR (Fig. 3B). In addition, although isolate Mp17 was

\section{Mp17}



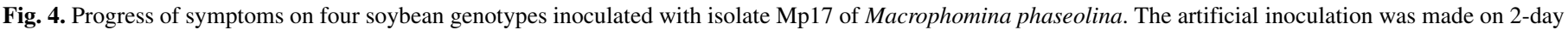

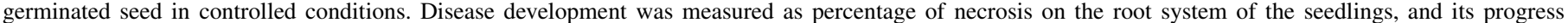
recorded every $48 \mathrm{~h}$ for 12 days postinoculation (dpi). 
the least aggressive on all genotypes when compared with the other isolates, it showed different degrees of aggressiveness in the genotypes tested, being significantly more aggressive when interacting with $\mathrm{DM} 6.2 \mathrm{i}$ RR than when interacting with Munasqa RR.

M. phaseolina is a polyphagous pathogen and there is currently no evidence of host specificity (Gupta et al. 2012). The in vitro infection method revealed significant differences in AUDPC values between the $M$. phaseolina isolates when interacting with the same soybean genotype. Also, these results showed that $M$. phaseolina isolates from Paraguay were more aggressive in controlled conditions than the ones collected in Argentina. In addition, it was demonstrated that the cultivar Munasqa RR showed a better response against all of the M. phaseolina isolates tested than DT 97-4290 (moderately resistant), as previously shown in the field trial, thus rendering the results obtained by this method more robust.

Based on our results, we suggest the existence of specific interactions between soybean genotypes and $M$. phaseolina genotypes in field and controlled conditions, a result which had not been demonstrated empirically before. These specific interactions between soybean elite cultivars and the local genotypes of the pathogen should be considered when developing improved charcoal rot management programs. Other studies have previously recommended that soybean genotypes, in general, adapted to a particular region should be tested with local isolates when screening genotypes resistant to charcoal rot (Sexton et al. 2016).

In conclusion, a better understanding of the genetic and pathogenic diversity and the specific interactions between soybean genotypes

Soybean genotypes

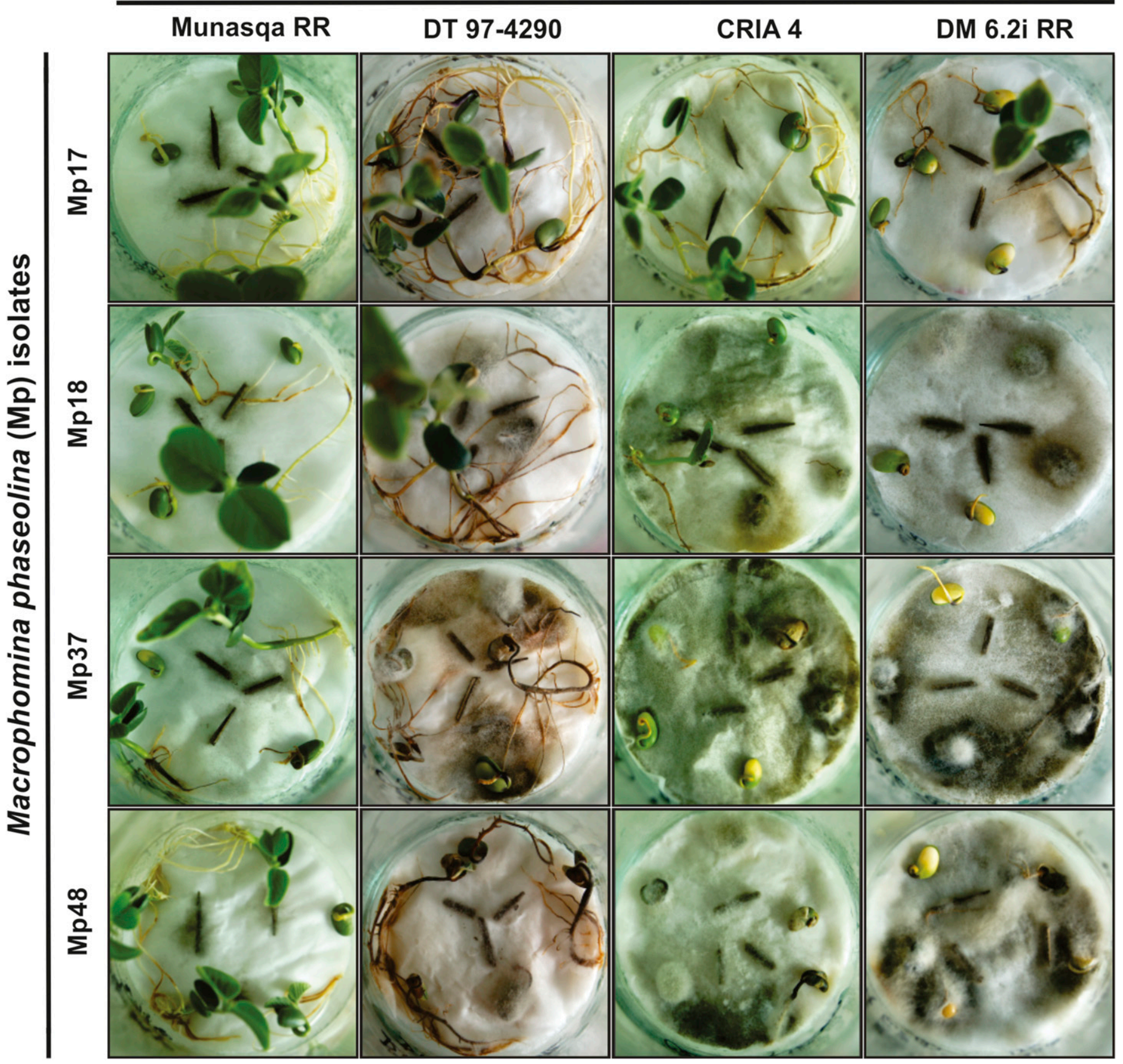

Fig. 5. Differential disease response of four soybean genotypes interacting with four representative Macrophomina phaseolina (Mp) isolates in controlled conditions at 12 days postinoculation (dpi). For each soybean genotype-M. phaseolina isolate interaction, one representative flask with five inoculated individuals is shown. 


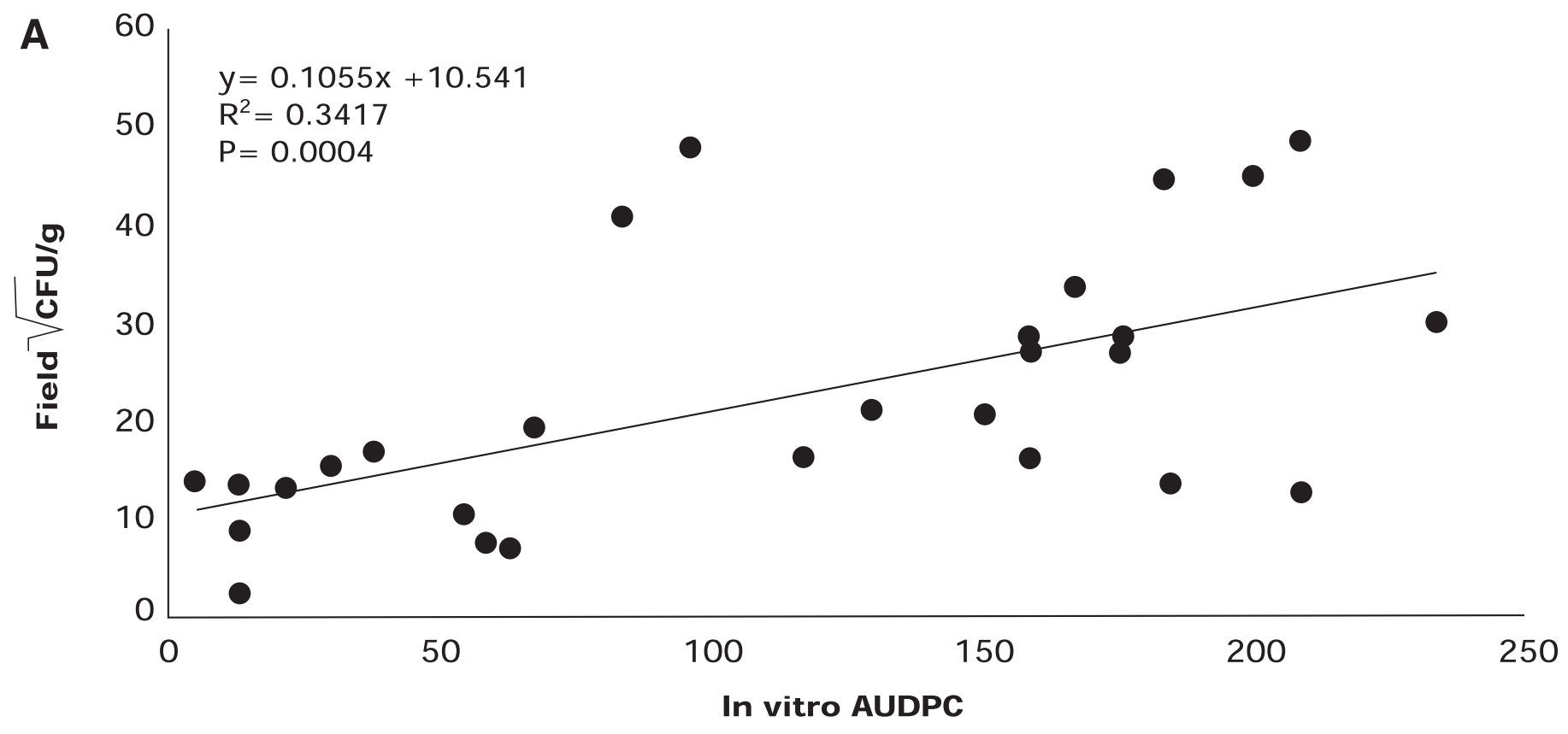

B

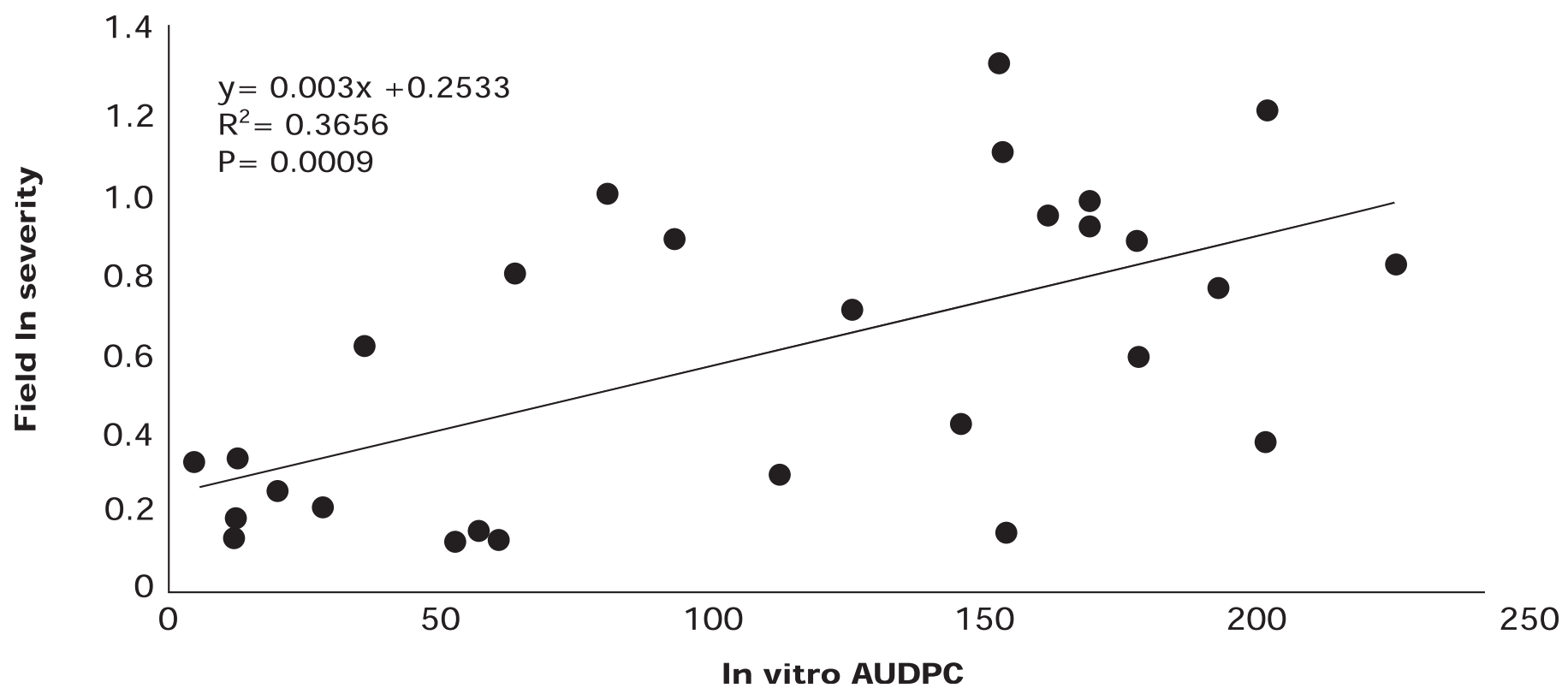

Fig. 6. Scatter plot showing the relationship between the area under the disease progress curve (AUDPC) data obtained for each combination of soybean genotypes and Macrophomina phaseolina isolates in controlled conditions and $\mathbf{A}$, the square root-transformed CFU/g of root and $\mathbf{B}$, In-transformed disease severity data from the field trial.

and M. phaseolina isolates will be useful to develop new technologies that would favor the sustainability of this crop. The present results indicate that the local elite cultivar Munasqa RR has the best performance against the seven $M$. phaseolina isolates tested, not only local ones but also those from Paraguay, in both field and controlled conditions. Resistance levels in Munasqa RR were even higher than in the moderately resistant genotype DT 97-4290. Therefore, Munasqa RR should be regarded as a new source of resistance, available to soybean breeders, a finding which will help in charcoal rot management in northwestern Argentina and in other soybeanproducing countries. Furthermore, a new simple, reproducible, and reliable method is now available to rapidly screen the disease response of soybean genotypes to $M$. phaseolina infection in controlled conditions and would be useful for other studies that aim to understand this complex plant-pathogen interaction. Finally, we demonstrated the existence of specific interactions between soybean and M. phaseolina genotypes.

\section{ACKNOWLEDGMENTS}

We thank R. Arias (United States Department of AgricultureAgricultural Research Service National Peanut Research Laboratory, Dawson, GA) for her technical support in SSR analysis.

\section{LITERATURE CITED}

Arias, R. S., Ray, J. D., Mengistu, A., and Scheffler, B. E. 2011. Discriminating microsatellites from Macrophomina phaseolina and their potential association to biological functions. Plant Pathol. 60:709-718.

Baird, R. E., Wadl, P. A., Allen, T., McNeill, D., Wang, X., Moulton, J. K., Rinehart, T. A., Abbas, H. K., Shier, T., and Trigiano, R. N. 2010. 
Variability of United States isolates of Macrophomina phaseolina based on simple sequence repeats and cross genus transferability to related genera within Botryosphaeriaceae. Mycopathologia 170:169-180.

Baird, R. E., Wadl, P. A., Wang, X., Johnson, D. H., Rinehart, T. A., Abbas, H. K., Shier, T., and Trigiano, R. N. 2009. Microsatellites from the charcoal rot fungus (Macrophomina phaseolina). Mol. Ecol. Resour. 9:946-948.

Balzarini, M. G., and Di Rienzo, J. A. 2013. Info-Gen: Software para análisis estadístico de datos genéticos. Online publication. Facultad de Ciencias Agropecuarias, Universidad Nacional de Córdoba, Argentina. https://www. info-gen.com.ar

Bowen, C., and Schapaugh, W. 1989. Relationships among charcoal rot infection, yield, and stability estimates in soybean blends. Crop Sci. 29:42-46.

Bressano, M., Giachero, M. L., Luna, C. M., and Ducasse, D. A. 2010. An in vitro method for examining infection of soybean roots by Macrophomina phaseolina. Physiol. Mol. Plant Pathol. 74:201-204.

Bristow, P., and Wyllie, T. 1984. Reaction of soybean cultivars to Macrophomina phaseolina as seedlings in the growth chamber and field. Trans. Mo. Acad. Sci. USA 18:5-10.

Dhingra, O. D., and Sinclair, J. B. 1978. Biology and Pathology of Macrophomina phaseolina. Universidade Federal de Vicosa, Vicosa, Brazil.

Di Rienzo, J., Casanoves, F., Balzarini, M., Gonzalez, L., Tablada, M., and Robledo, Y. C. 2011. InfoStat versión 2011. Online publication. Grupo InfoStat, Facultad de Ciencias Agropecuarias, Universidad Nacional de Córdoba, Argentina. http://www.infostat.com.ar

Fehr, W. R., Caviness, C. E., Burmood, D. T., and Pennington, J. S. 1971. Stage of development descriptions for soybeans, Glycine max (L.). Merrill. Crop Sci. 11:929-931.

Gupta, G. K., Sharma, S. K., and Ramteke, R. 2012. Biology, epidemiology and management of the pathogenic fungus Macrophomina phaseolina (Tassi) Goid with special reference to charcoal rot of soybean (Glycine max (L.) Merrill). J. Phytopathol. 160:167-180.

Highton, R. 1993. The relationship between the number of loci and the statistical support for the topology of UPGMA trees obtained from genetic distance data. Mol. Phylogenet. Evol. 2:337-343.

Jana, T. K., Singh, N. K., Koundal, K. R., and Sharma, T. R. 2005. Genetic differentiation of charcoal rot pathogen, Macrophomina phaseolina, into specific groups using URP-PCR. Can. J. Microbiol. 51:159-164.

Madden, L. V., Hughes, G., and van den Bosch, F. 2007. The Study of Plant Disease Epidemics. American Phytopathological Society Press, St. Paul, MN.

Mayék-Pérez, N., López-Castañeda, C., González-Chavira, M., Garcia-Espinosa, R., Acosta-Gallegos, J., de la Vega, O. M., and Simpson, J. 2001. Variability of Mexican isolates of Macrophomina phaseolina based on pathogenesis and AFLP genotype. Physiol. Mol. Plant Pathol. 59:257-264.

Mengistu, A., Bond, J., Nelson, R., Rupe, J., Shannon, G., Arelli, P., and Wrather, A. 2013a. Identification of soybean accessions resistant to Macrophomina phaseolina by field screening and laboratory validation. Online publication. Plant Health Prog. 14. doi.org/10.1094/PHP-2013-0318-01-RS

Mengistu, A., Ray, J. D., Smith, J. R., and Paris, R. L. 2007. Charcoal rot disease assessment of soybean genotypes using a colony-forming unit index. Crop Sci. 47:2453-2461.

Mengistu, A., Reddy, K. N., Bellaloui, N., Walker, E. R., and Kelly, H. M. 2013b. Effect of glyphosate on Macrophomina phaseolina in vitro and its effect on disease severity of soybean in the field. Crop Prot. 54:23-28.

Mengistu, A., Smith, J. R., Ray, J. D., and Bellaloui, N. 2011. Seasonal progress of charcoal rot and its impact on soybean productivity. Plant Dis. 95:1159-1166

Mihail, J. D., and Taylor, S. J. 1995. Interpreting variability among isolates of Macrophomina phaseolina in pathogenicity, pycnidium production, and chlorate utilization. Can. J. Bot. 73:1596-1603.
Milbourne, D., Meyer, R., Bradshaw, J. E., Baird, E., Bonar, N., Provan, J., Powell, W., and Waugh, R. 1997. Comparison of PCR-based marker systems for the analysis of genetic relationships in cultivated potato. Mol. Breed. 3:127-136.

Muñoz-Cabañas, R. M., Hernández-Delgado, S., and Mayek-Pérez, N. 2005. Análisis patogénico y genético de Macrophomina phaseolina (Tassi) Goid. en diferentes hospedantes. Rev. Mex. Fitopatol. 23:11-18.

Murray, M., and Thompson, W. F. 1980. Rapid isolation of high molecular weight plant DNA. Nucleic Acids Res. 8:4321-4326.

Nei, M. 1973. Analysis of gene diversity in subdivided populations. Proc. Natl. Acad. Sci. USA 70:3321-3323.

Orrego Fuente, A. L., Grabowski, C., Soilan, L., Ferreira, L., and Del Valle, C. 2009. Distribución geográfica de Macrophomina phaseolina en los cultivos de soja, sésamo y maní. Pages 27-34 in: Macrophomina phaseolina, hongo causante de la pudrición carbonosa del tallo. A. L. Orrego Fuente, ed. Alamo, S.A., FCA, UNA/INBIO, San Lorenzo, Paraguay.

Paris, R. L., Mengistu, A., Tyler, J., and Smith, J. 2006. Registration of soybean germplasm line DT 97-4290 with moderate resistance to charcoal rot. Crop Sci. 46:2324-2325.

Pawlowski, M. L., Hill, C. B., and Hartman, G. L. 2015. Resistance to charcoal rot identified in ancestral soybean germplasm. Crop Sci. 55: 1230-1235.

Ploper, L., González, V., Vázquez de Ramallo, N., Gálvez, M., and Devani, M. 2001. Presencia de la podredumbre carbonosa del tallo de la soja en el centro y noroeste argentino. Avance Agroind. 22:30-34.

Reznikov, S. 2016. Evaluación de la diversidad genética de Macrophomina phaseolina en el Norte argentino y búsqueda de alternativas de manejo sostenible de la podredumbre carbonosa en soja. Tesis Doctoral, Facultad de Bioquímica, Química y Farmacia., Universidad Nacional de Tucumán, Tucumán, Argentina.

Romero Luna, M. P., Mueller, D., Mengistu, A., Singh, A. K., Hartman, G. L., and Awise, K. 2017. Advancing our understanding of charcoal rot in soybeans. J. Integr. Pest Manage. 8:1-8.

Saleh, A. A., Ahmed, H. U., Todd, T. C., Travers, S. E., Zeller, K. A., Leslie, J. F., and Garret, K. A. 2010. Relatedness of Macrophomina phaseolina isolates from tallgrass prairie, maize, soybean and sorghum. Mol. Ecol. 19:79-91.

Sarr, M. P., Ndiaye, M. B., Groenewald, J. Z., and Crous, P. W. 2014. Genetic diversity in Macrophomina phaseolina, the causal agent of charcoal rot. Phytopathol. Mediterr. 53:250-268.

Sexton, Z. F., Hughes, T. J., and Wise, K. A. 2016. Analyzing isolate variability of Macrophomina phaseolina from a regional perspective. Crop Prot. 81:9-13.

Smith, G. S., and Carvil, O. N. 1997. Field screening of commercial and experimental soybean cultivars for their reaction to Macrophomina phaseolina. Plant Dis. 81:363-368.

Su, G., Suh, S. O., Schneider, R. W., and Russin, J. S. 2001. Host specialization in the charcoal rot fungus, Macrophomina phaseolina. Phytopathology 91:120-126.

Twizeyimana, M., Hill, C., Pawlowski, M., Paul, C., and Hartman, G. 2012. A cut-stem inoculation technique to evaluate soybean for resistance to Macrophomina phaseolina. Plant Dis. 96:1210-1215.

Wrather, A., Shannon, G., Balardin, R., Carregal, L., Escobar, R., Gupta, G., Ma, Z., Morel, W., Ploper, D., and Tenuta, A. 2010. Effect of diseases on soybean yield in the top eight producing countries in 2006. Online publication. Plant Health Prog. 11. doi.org/10.1094/PHP-2010-0102-01-RS

Yap, I., and Nelson, R. J. 1996. Winboot: A program for performing bootstrap analysis of binary data to determine the confidence limits of UPGMA-based dendrograms. IRRI Discuss. Pap. Ser. No. 14. International Rice Research Institute, Manila, Philippines. 